\title{
Aspectos relacionados à violência ocupacional sofrida pelos profissionais de enfermagem
}

\author{
Aspects related to occupational violence suffered by nursing professionals
}

\begin{abstract}
Aspectos relacionados con la violencia laboral que sufren los profesionales de enfermeira
Dayane da Silva Tavares ${ }^{1 *}$, Alessandra Baraúna da Silva ${ }^{1}$, Anne Beatriz Moreira da Silva ${ }^{1}$, Christian Catique Barbosa1 ${ }^{1}$, Giovanna da Silva Souza ${ }^{1}$, Damara Raína Lozano Videira ${ }^{1}$, Ellen Juliany Duarte Prestes $^{1}$, Mayara Greyce Lopes Mendonça ${ }^{1}$, Silvana Nunes Figueiredo'.
\end{abstract}

\section{RESUMO}

Objetivo: Pesquisar sobre a violência ocupacional, identificando seus devidos fatores, cuja esta é sofrida pelos profissionais de enfermagem em seu ambiente laboral. Métodos: Trata-se de um estudo descritivo exploratório onde optou-se por métodos de Revisão Sistemática e Metanálise, caracterizada pelo delineamento do estudo, conduzindo este de forma a realizar uma descrição objetiva da evidência sumarizada, que analisa estatisticamente as evidências reunidas, sendo apropriada para combinar os resultados em diferentes estudos. Resultados: Evidencia-se que muitos profissionais sofrem alguns tipos de violência no trabalho, entre elas: violência verbal, psicológica, assédio moral e violência física. $E$ entres os seus agressores estão os pacientes, acompanhantes, colegas de trabalho e seus superiores. Considerações finais: $O$ presente trabalho evidencia que a violência no ambiente laboral do profissional de enfermagem é algo recorrente, porém, dificilmente denunciado, o que faz com que essa problemática seja pouco estudada, sendo necessário a criação de um protocolo tanto para prevenção do problema quanto para sua solução.

Palavras-chave: Profissionais de Enfermagem, Violência ocupacional, Riscos ocupacionais.

\begin{abstract}
Objective: Research on occupational violence, identifying its due factors, which are suffered by nursing professionals in their work environment. Methods: This is an exploratory descriptive study in which systematic review and meta-analysis methods were chosen, characterized by the design of the study, leading it in order to carry out an objective description of the summarized evidence, which statistically analyzes the evidence gathered, being appropriate to combine the results in different studies. Results: It is evident that many professionals suffer some types of violence at work, among them: verbal, psychological, moral harassment and physical violence. Among its aggressors are patients, companions, co-workers and their superiors. Final considerations: The present study shows that violence in the nursing professional's work environment is recurrent, however, it is difficult to denounce it, which causes this problem to be little studied, being necessary the creation of a protocol for both the prevention of the problem and for your solution.
\end{abstract}

Keywords: Nursing professionals, Occupational violence, Occupational risks.

\section{RESUMEN}

Objetivo: Investigar sobre la violencia laboral, identificando sus factores debidos, que padecen los profesionales de enfermería en su entorno laboral. Métodos: Se trata de un estudio descriptivo exploratorio en el que se eligieron métodos de revisión sistemática y metanálisis, caracterizados por el diseño del estudio, conduciéndolo a realizar una descripción objetiva de la evidencia resumida, que analiza estadísticamente la

${ }^{1}$ Centro Universitário FAMETRO, Manaus - AM. *E-mail: enayadst@gmail.com

PUBLICADO EM: 2/2020 
evidencia recolectada, siendo apropiado combinar los resultados en diferentes estudios. Resultados: Es evidente que muchos profesionales sufren algún tipo de violencia en el trabajo, entre ellos: acoso verbal, psicológico, moral y violencia física. Entre sus agresores se encuentran pacientes, acompañantes, compañeros de trabajo y sus superiores. Consideraciones finales: El presente estudio muestra que la violencia en el ámbito laboral del profesional de enfermería es recurrente, sin embargo, es difícil denunciarla, lo que ocasiona que este problema sea poco estudiado, siendo necesaria la elaboración de un protocolo tanto para la prevención del problema como para para su solución.

Palabras clave: Profesionales de enfermería, Violencia laboral, Riesgos laborales.

\section{INTRODUÇÃO}

Ao passo que a sociedade progrediu, a globalização e industrialização se intensificaram gerando mudanças consideráveis no dinamismo do trabalho. Com a inclusão de novas tecnologias, como informática, robótica, microeletrônica, entre outras, somado às alterações na composição do desempenho do trabalho, terminaram por modificar as linhas produtivas dos países, além de interferir na saúde dos trabalhadores (SOUZA AAM, et al., 2014).

O trabalho é algo que o ser humano não pode viver sem, principalmente por ser o que irá lhe trazer renda para suprir suas necessidades, além de significar a razão de orgulho e satisfação para a maioria das pessoas. Através do trabalho conquistamos nossos objetivos de vida, mas por outro lado, esse mesmo trabalho que deveria nos dá satisfação e estabilidade, também pode nos trazer sofrimento, sentimento de insuficiência, doenças e outros agravos (MARTINS JT, et al., 2014).

O meio de trabalho, enquanto espaço coletivo, também é atingido fortemente pelo aumento da violência. No meio dos trabalhadores de saúde, os profissionais de enfermagem juntamente com a sua equipe estão mais expostos a sofrerem algum tipo de agressão, seja física ou verbal. Isto se dá pelo motivo de que a equipe da assistência está em constante contato com os pacientes e acompanhantes, e consequentemente acabam por serem alvos de inúmeras injúrias motivadas pela insatisfação com o atendimento (VASCONCELLOS IRR, et al., 2012).

Segundo a Organização Internacional do Trabalho (OIT), a violência no local de trabalho é a execução de uma pessoa contra outra pessoa que leva a agressão, ofensa, humilhação ou prejuízo no seu trabalho e muitas vezes danos irreparáveis. Diante disso o trabalhador é considerado como um dos elementos que estão sob alto risco em todas as áreas do trabalho incluindo ambiente hospitalar (VASCONCELLOS IRR, et al., 2012).

Diante disso, ao desempenhar seu trabalho os profissionais de saúde que estão em contato diariamente com pessoas de diversos problemas de saúde, que se encontram muitas vezes estressados pelo fato de estarem doente acabam agindo de forma violenta com o trabalhador e isso acaba gerando impactos negativos na saúde e no desempenho do trabalhador, acarretando adoecimento com o mesmo e insatisfação com a profissão (TSUKAMOTO SAS, et al., 2019).

Com esse tipo de conduta à saúde do trabalhador, ele sofre danos como o desanimo, desvalorização, insegurança, falta de confiança, depressão, raiva, ansiedade e irritabilidades geradas sobre o funcionário. Além disto, existe justamente os custos econômicos a corporação empregadora, como prejuízos ou rompimento de convívio interpessoal, desestruturação da organização do trabalho, necessidade de mudar os recursos em resultados de fama mais econômica, diminuição na produção e danos no produto e imagem da empresa (SOUZA AAM, et al., 2014).

Contudo, o presente trabalho teve como objetivo geral pesquisar sobre a violência ocupacional sofrida pelos profissionais de enfermagem em seu ambiente laboral.

\section{MÉTODOS}

Trata-se de um estudo descritivo exploratório onde optou-se por métodos de Revisão Sistemática e Metanálise, visto que a revisão sistemática caracteriza o contorno do estudo conduzindo este de forma, 
realizando descrição objetiva da evidência sumarizada, enquanto que o termo metanálise caracteriza o método estatístico de analisar as evidências reunidas, apropriada para combinar a estatística dos resultados em diferentes estudos (BAENA CP, 2014).

Para atingir o objetivo, foi definido a seguinte pergunta norteadora do estudo: por que os profissionais de enfermagem têm o maior risco de sofrer violência no ambiente de trabalho? Realizando-se assim a investigação a respeito da Violência Ocupacional, possibilitando compreensão acerca dos aspectos relacionados a esse fenômeno sofrido pelos profissionais de enfermagem.

A busca por publicações cientificas foi realizada em janeiro a julho de 2020, utilizando-se bibliotecas virtuais: Scientific Electronic Library Online (SCIELO) e Literatura Latino-Americana e do Caribe em Ciências da Saúde (LILACS), mediante os seguintes descritores "Profissionais de Enfermagem", "Violência Ocupacional", "Riscos Ocupacionais". No que tange aos critérios de elegibilidade: artigos publicados nos últimos 10 anos 2010-2020, português, inglês, completos e disponíveis gratuitamente. Critérios de inelegibilidade: artigos em forma de resumo, monografias, dissertação de mestrado.

\section{RESULTADOS/ DISCUSSÃO}

Após a busca dos artigos através das bases de dados científicas na Biblioteca Virtual em Saúde, apresentamos os seguintes resultados através do fluxograma: Biblioteca Virtual em Saúde, apresentamos os seguintes resultados:

Figura 1 - Fluxograma.

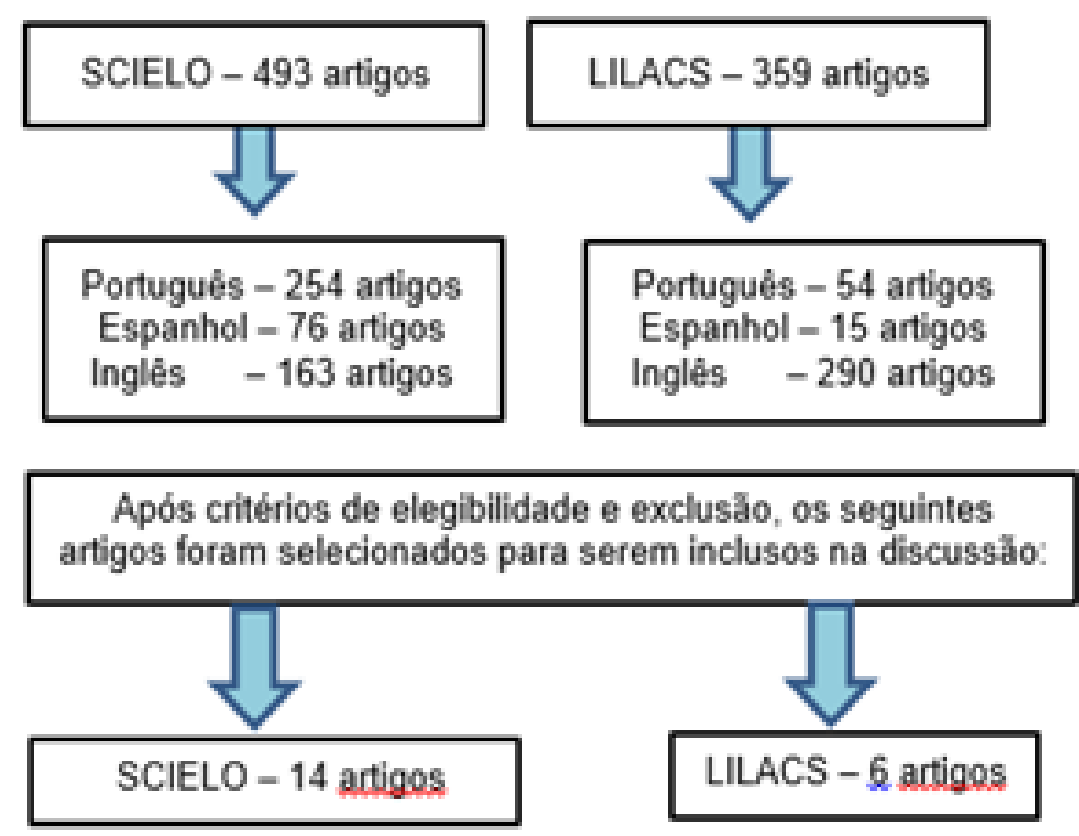

Fonte: Tavares DS, et al., 2020.

Se tratando da origem da enfermagem no geral, lembra-se primeiramente Florence Nightingale. Considerada como a pioneira da enfermagem moderna, Florence começa sua história na guerra da Criméia, em 1854, onde reorganizou o atendimento aos soldados feridos da guerra salvando milhares de vidas, trabalhando sempre com maestria e organização, visando o bom cuidado e a higiene, o que deu a enfermagem mais reconhecimento. Fundou também a Escola de Enfermagem no Hospital Saint Thomas, em 1860, iniciando o período conhecido como Enfermagem Moderna (COSTA R, et al., 2009).

Florence ganhou o apelido de "Dama da Lâmpada", pois sempre percorria nas enfermarias com uma lamparina, objeto ao qual se tornou posteriormente, o símbolo da profissão de enfermagem (FRAZÃO D, 2020). 
Quadro 1 - Coleta de dados bibliográficos.

\begin{tabular}{|c|c|c|c|c|c|}
\hline & AUTOR & TÍTULO & IDIOMA & PLATAFORMA & RESULTADOS \\
\hline 1 & $\begin{array}{l}\text { Barbosa R, et al. } \\
(2011)\end{array}$ & $\begin{array}{l}\text { Violência psicológica na prática profissional da } \\
\text { enfermeira }\end{array}$ & Português & SCIELO & $\begin{array}{l}\text { A maioria dos agressores foram mulheres, tanto } \\
\text { colegas da área quanto outros profissionais; }\end{array}$ \\
\hline 2 & $\begin{array}{l}\text { Vasconcellos I, et al. } \\
\qquad(2012)\end{array}$ & $\begin{array}{l}\text { Violência ocupacional sofrida pelos profissionais } \\
\text { de enfermagem do serviço de pronto atendimento } \\
\text { hospitalar }\end{array}$ & Português & SCIELO & $\begin{array}{l}\text { Elo entre profissional e cliente é o mais próximo, } \\
\text { logo, acabaram sofrendo violência por conta de } \\
\text { insatisfação; }\end{array}$ \\
\hline 3 & $\begin{array}{l}\text { Fontes K, et al. } \\
\qquad(2013)\end{array}$ & $\begin{array}{l}\text { Fatores associados ao assédio moral no ambiente } \\
\text { laboral do enfermeiro }\end{array}$ & Inglês & SCIELO & $\begin{array}{l}\text { Nos últimos anos estudos mostram que são os } \\
\text { enfermeiros que foram vítimas de violência no } \\
\text { ambiente laboral e esclarece instabilidade que } \\
\text { esses profissionais sofrem. }\end{array}$ \\
\hline 4 & $\begin{array}{l}\text { Monte } \mathrm{P} \text {, et al. } \\
\quad(2013)\end{array}$ & $\begin{array}{l}\text { Estresse dos profissionais enfermeiros que atuam } \\
\text { na unidade de terapia intensiva }\end{array}$ & Português & SCIELO & $\begin{array}{l}\text { A UTI pode gerar muita ansiedade aos } \\
\text { profissionais de enfermagem pela complexidade } \\
\text { do trabalho as condições idem. }\end{array}$ \\
\hline 5 & Andrade CB, et al. (2015) & $\begin{array}{l}\text { Assédio moral do trabalho e sua complexidade: } \\
\text { revisando as produções científicas }\end{array}$ & $\begin{array}{l}\text { Inglês / } \\
\text { Português }\end{array}$ & LILACS & $\begin{array}{l}\text { O assédio moral é um tipo de violência que acaba } \\
\text { sendo pouco investigada, devido à falta de } \\
\text { denúncias, pode trazer prejuízos físico e } \\
\text { psiquiátricos por exemplo; }\end{array}$ \\
\hline 6 & $\begin{array}{l}\text { Teixeira A, et al. } \\
\qquad(2016)\end{array}$ & $\begin{array}{l}\text { Bullying no trabalho: percepção e impacto na } \\
\text { saúde mental e vida pessoal dos enfermeiros }\end{array}$ & Português & SCIELO & $\begin{array}{l}\text { Conclui-se como o bullying pode ser prejudicial no } \\
\text { trabalho comprometendo o desempenho } \\
\text { profissional da vítima. }\end{array}$ \\
\hline 7 & $\begin{array}{l}\text { Bordignon M e Monteiro Ml } \\
\qquad(2016)\end{array}$ & $\begin{array}{l}\text { Violência no trabalho da Enfermagem: um olhar às } \\
\text { consequências }\end{array}$ & Português & SCIELO & $\begin{array}{l}\text { Consta o quando o estresse devido à violência } \\
\text { sofrida pode influenciar no serviço e na saúde do } \\
\text { profissional de enfermagem. }\end{array}$ \\
\hline 8 & $\begin{array}{l}\text { Angelim RCM e Rocha } \\
\text { GSA (2016) }\end{array}$ & $\begin{array}{l}\text { Produção científica acerca das condições de } \\
\text { trabalho da enfermagem em serviços de urgência } \\
\text { e emergência }\end{array}$ & $\begin{array}{l}\text { Inglês / } \\
\text { Português }\end{array}$ & LILACS & $\begin{array}{l}\text { Conclui-se que os profissionais são expostos a } \\
\text { doenças infecciosas, além de correrem o risco de } \\
\text { sofrer violência todos os dias, além da carga de } \\
\text { horário exaustiva; }\end{array}$ \\
\hline 9 & $\begin{array}{l}\text { Vieira GLC } \\
\quad(2017)\end{array}$ & $\begin{array}{l}\text { Agressão física contra técnicos de enfermagem em } \\
\text { hospitais psiquiátricos }\end{array}$ & Português & SCIELO & $\begin{array}{l}\text { Os profissionais relataram já ter passado por } \\
\text { experiências de agressão física no trabalho e os } \\
\text { mesmos relatam se sentir inseguros no ambiente } \\
\text { de trabalho. }\end{array}$ \\
\hline 10 & $\begin{array}{l}\text { Pedro D, et al. } \\
\qquad(2017)\end{array}$ & $\begin{array}{l}\text { Violência ocupacional na equipe de enfermagem: } \\
\text { análise à luz do conhecimento produzido }\end{array}$ & Português & SCIELO & $\begin{array}{l}\text { A desorganização do trabalho, acarreta em } \\
\text { violência verbal aos trabalhadores; } \\
\text { Como prioridade dos problemas, o assédio verbal } \\
\text { é muito utilizado nas ações de liderança; }\end{array}$ \\
\hline 11 & Scaramal DA, et al. (2017) & $\begin{array}{l}\text { Violência física ocupacional em serviços de } \\
\text { urgência e emergência hospitalares: percepções } \\
\text { de trabalhadores de enfermagem. }\end{array}$ & $\begin{array}{l}\text { Inglês / } \\
\text { Português }\end{array}$ & LILACS & $\begin{array}{l}\text { Foi relatado que alguns pacientes agrediram os } \\
\text { profissionais em todas as esferas de agressão. } \\
\text { Contudo os primeiros a serem vítimas das suas } \\
\text { frustrações são os profissionais de enfermagem; }\end{array}$ \\
\hline
\end{tabular}




\begin{tabular}{|c|c|c|c|c|c|}
\hline & AUTOR & TíTULO & IDIOMA & PLATAFORMA & RESULTADOS \\
\hline 12 & $\begin{array}{c}\text { Fernandes APFC e Passos } \\
\text { JP (2018) }\end{array}$ & $\begin{array}{l}\text { Delineamento da violência sofrida pela equipe de } \\
\text { enfermagem na emergência hospitalar }\end{array}$ & Português & LILACS & $\begin{array}{l}\text { Relata-se resistência sob a gestão hospitalar como } \\
\text { fator que desencadeia a violência, estudos focando } \\
\text { na melhoria de todos aspectos para prevenção de } \\
\text { agressões também; }\end{array}$ \\
\hline 13 & Dal Pai D, et al. (2018) & $\begin{array}{l}\text { Violência física e psicológica perpetrada no } \\
\text { trabalho em saúde }\end{array}$ & Português & SCIELO & $\begin{array}{l}\text { Mulheres na maioria dos casos foram as vítimas } \\
\text { dos ataques seja qual for a esfera e os agressores } \\
\text { eram acompanhantes ou colegas de trabalho. }\end{array}$ \\
\hline 14 & $\begin{array}{l}\text { Gonçalves AR, et al. } \\
(2018)\end{array}$ & $\begin{array}{l}\text { Stress e engagement na profissão de enfermagem: } \\
\text { análise de dois contextos internacionais }\end{array}$ & Português & SCIELO & $\begin{array}{l}\text { Estudos apontam alguns dos fatores causadores } \\
\text { do stress são as grandes jornadas de trabalho, a } \\
\text { pressão do tempo, o contato direto com o } \\
\text { sofrimento e a morte. }\end{array}$ \\
\hline 15 & Tsukamoto S, et al. (2019) & $\begin{array}{l}\text { Violência ocupacional na equipe de enfermagem: } \\
\text { prevalência e fatores associados }\end{array}$ & Português & SCIELO & $\begin{array}{l}\text { A equipe de enfermagem enfrenta violência física } \\
\text { no trabalho, principalmente pelos pacientes e seus } \\
\text { acompanhantes bem como sofrem violência de } \\
\text { seus superiores; }\end{array}$ \\
\hline 16 & Lucena PLC, et al. (2019) & $\begin{array}{l}\text { Testemunhas de assédio moral, na enfermagem: } \\
\text { identificando características desse fenômeno, } \\
\text { sentimentos e estratégias de enfrentamento }\end{array}$ & Português & LILACS & $\begin{array}{l}\text { O resultado deste estudo mostra que a assédio } \\
\text { moral é deferido pelos superiores, algumas } \\
\text { testemunhas relatam que os assédios duram anos; }\end{array}$ \\
\hline 17 & Souza JSR, et al. (2020) & $\begin{array}{l}\text { Relações interpessoais entre enfermeiro-paciente } \\
\text { na perspectiva da violência atual }\end{array}$ & $\begin{array}{l}\text { Inglês / } \\
\text { Português }\end{array}$ & LILACS & $\begin{array}{l}\text { Observou-se que a violência horizontal é muito } \\
\text { presente no hospital e a enfermagem tem risco de } \\
\text { sofrer qualquer tipo de violência todos os dias no } \\
\text { local de trabalho; }\end{array}$ \\
\hline 18 & Carvalho AE, et al. (2020) & $\begin{array}{l}\text { Estresse dos profissionais de enfermagem } \\
\text { atuantes no atendimento pré-hospitalar }\end{array}$ & Português & SCIELO & $\begin{array}{l}\text { Observou-se que os profissionais mais atingidos } \\
\text { pelo estresse, foram as do sexo feminino, devido } \\
\text { ao ambiente laboram insalubre, dublas ou triplas } \\
\text { jornadas de trabalho; }\end{array}$ \\
\hline 19 & Santos K, et al. (2020) & $\begin{array}{l}\text { Perfil da equipe de enfermagem de unidades } \\
\text { ambulatoriais universitárias: considerações para a } \\
\text { saúde do trabalhador }\end{array}$ & Inglês & SCIELO & $\begin{array}{l}\text { Nesse estudo de dimensão nacional e } \\
\text { internacional, relata-se as doenças que um } \\
\text { enfermeiro pode desenvolver no ambiente laboral } \\
\text { e diversos fatores que desencadeia tal } \\
\text { problemática; }\end{array}$ \\
\hline 20 & Santana LC, et al. (2020) & $\begin{array}{l}\text { Estresse ocupacional em profissionais de } \\
\text { enfermagem de um hospital universitário }\end{array}$ & Português & SCIELO & $\begin{array}{l}\text { Nos últimos anos o estresse decorrente de } \\
\text { sobrecarga de trabalho, situações precárias em } \\
\text { todas vertentes insatisfatórias do cotidiano foram } \\
\text { citados bem como fatores para melhoria do quadro. }\end{array}$ \\
\hline
\end{tabular}

Fonte: Tavares DS, et al., 2020. 
Gráfico 1 - Análise da violência no trabalho.

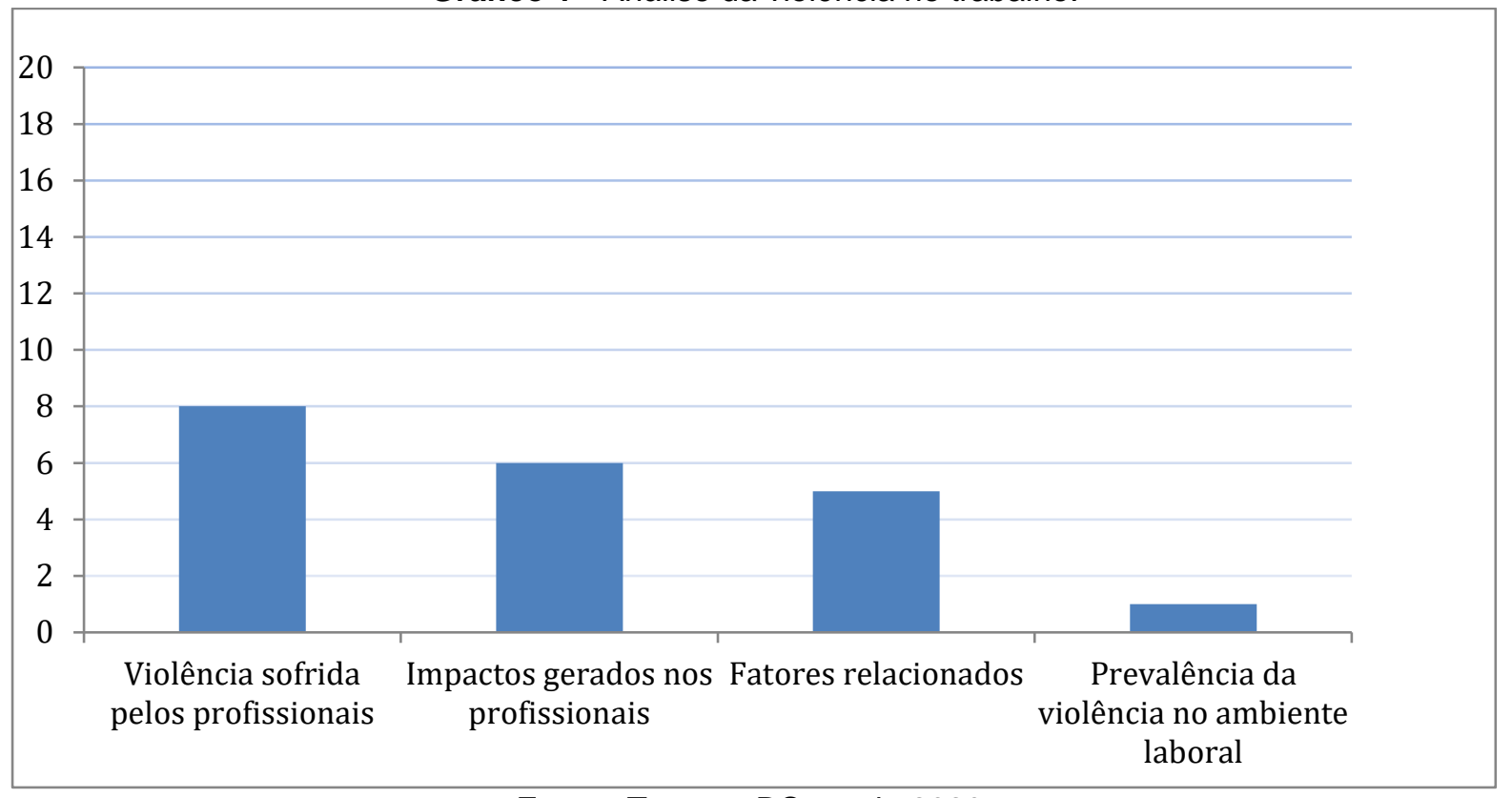

Fonte: Tavares DS, et al., 2020.

Analisando os dados, pode-se observar que oito artigos (40\%) abordam o tema com clareza, expondo bem a realidade atual do que o profissional acaba enfrentando diante da violência sofrida por eles, seis artigos (30\%) mostram os resultados da violência sofrida e impactos que gera no profissional, cinco artigos (25\%) enfatizam com clareza os fatores que levam o profissional a passar pela violência, um artigo (5\%) mostra que a violência está crescendo e que as testemunhas que presenciam tal ação acabam achando normal, desamparando vítimas.

Na enfermagem brasileira, o nome mais conhecido é de Ana Justina Ferreira Néri, onde sua história como enfermeira começou em 1864, no Paraguai, prestando cuidados aos feridos de guerra. Ela criou uma campanha, sendo a primeira enfermeira a realizar atendimentos em sua própria casa, tornando o cuidado aos feridos mais sistematizado. Foi nomeada como madrinha da enfermagem brasileira, homenageada pela primeira escola oficial de enfermagem ao qual foi dada o nome de Ana Néri, hoje conhecida como Escola de Enfermagem Ana Néri da UFRJ (GRIZARD R e VIEIRA ETS, 2008).

A atividade ocupacional e laboral é algo através do qual conquistamos objetivos de vida. De modo particular, a enfermagem do trabalho é caracterizada como especialidade consolidada não somente para reconhecimento pela área de saúde, mas de forma geral no contexto do trabalho e da sociedade atualmente. Sendo assim, o profissional da enfermagem ganha cada vez mais espaço nas organizações, contribuindo com a qualidade de vida do trabalhador e orientando quanto à prevenção de riscos ocupacionais, gerenciando devida assistência e maior responsabilidade (MARTINS et al., 2014).

A violência é definida como qualquer ação intencional de ferir moralmente, fisicamente ou psicologicamente qualquer indivíduo, seja ele por ter uma raça, religião ou cultura diferente ou não. Há vários tipos de violência, entre elas podemos mencionar, abuso físico, abuso sexual, abuso psicológico, negligência ou abandono, violência intrafamiliar, violência doméstica, bulliyng, violência ocupacional, entre outros (COELHO EBS, et al., 2014).

O conceito de violência ocupacional se caracteriza pela violência praticada em uma instituição, pública ou privada, com fins lucrativos ou não, exercida por pessoas de ambos os sexos. Dentre elas cita-se as psicológicas e físicas, sendo práticas. A consequência que isso pode trazer ao trabalhador são várias, como: ansiedade, depressão, diminuição da confiança quanto a sua capacidade e competência como funcionário e como ser humano, entre outras (APAV, 2015). 
De acordo com Berlingieri A (2015), a violência externa é definida como aquela que é provocada por um indivíduo que não faz parte da equipe de trabalho da instituição, ou seja, desconhecido. Neste caso, os profissionais de saúde têm um risco aumentado de sofrerem este tipo de violência, principalmente se a localização da instituição de trabalho for em um lugar mais carente, como periferias e locais com alto consumo de entorpecentes.

A violência provocada pelo cliente é aquela exercida pelos usuários do serviço de saúde, tanto dos próprios pacientes quanto dos seus acompanhantes, já que estão na linha de frente do atendimento hospitalar e podem recepcionar diversos casos, onde o sujeito possa estar alterado. A violência interna ou institucional é aquela onde trabalhadores da mesma instituição passam a ter conflitos entre si (BERLINGIERI A, 2015).

A Violência psicológica que é mais complexa, compreendida como síndrome psicossocial multidimensional. Psicossocial por que afeta tanto o indivíduo como a equipe de trabalho e a organização, provocando perturbações tanto individuais como de uma forma coletiva gerando conflitos externos; e multidimensional por que se apresenta em diferentes tipos de sintomas, específicos e não específicos, assim sendo difícil de ser diagnosticado (BARBOSA R, et al., 2011).

Violência nas redes sociais, também conhecida como cyberbullying, é algo que vem crescendo muito no país e no mundo. Como uma terra sem lei, algumas pessoas acabam se mostrando quem realmente são, de uma forma ruim, deixando de lado a moralidade, assim usando as redes sociais para ofender diretamente determinado grupo de pessoas, seja desde divergências religiosas e políticas, até o racismo, homofobia e "brincadeiras" sobre a aparência alheia, entre outros (BERGAMASCKI G, 2018).

A agressão verbal sendo a que mais é utilizada como forma de violência. Embora não seja tão impactante quanto a agressão física, pode gerar consequências sérias ao trabalhador, seja pelo curto ou longo prazo, como: afetar a qualidade e eficiência do serviço de enfermagem prestados, pode causar um distanciamento em relação aos pacientes e colegas de trabalho, desconfiança, pode começar a se questionar quanto o valor da sua profissão, caindo em depressão (VASCONCELLOS, et al., 2012).

Segundo Tsukamoto SAS, et al. (2019), de 242 trabalhadores entrevistados, quanto à autoria da violência, prevaleceram os pacientes e os acompanhantes (63,3\%), seguido dos colegas de trabalho $(24,5 \%)$ e chefes e supervisores (12,2\%). Levando em consideração esse estudo, que a maioria dos profissionais são do sexo feminino, os agressores da maioria eram do sexo masculino, e em $50 \%$ dos casos a vítima e agressor eram do sexo oposto.

Os profissionais de enfermagem além de enfrentar as dificuldades em circunstancias laborais, como a vivencia de sofrimento, por exemplo a morte e dor decorrente de perda de um paciente, além de algumas vezes não terem condições laborais de qualidade para prestar um melhor serviço à comunidade, ainda pode sofrer consequências profissionais devido à violência sofrida, como deficiência do desempenho da função (BORDIGNON M e MONTEIRO MI, 2016).

Comparados a outros profissionais de saúde, os profissionais de enfermagem são os mais atingidos pela violência física e verbal. Em hospitais psiquiátricos essas taxas são ainda maiores, o que varia entre 1,7\% a $71,6 \%$, indicando que as características dos pacientes podem ser fatores que favorecem esse tipo de episódio violento contra os profissionais. As taxas de violência física especificamente podem chegar a representar $17 \%$ dos casos. O tempo de contato com o paciente, dimensionamento do $\mathrm{RH}$ e experiência profissional podem ser outros fatores que podem desencadear os eventos de violência (VIEIRA GLC, 2017).

O assédio moral exercido pelos superiores pode trazer muitas consequências aos profissionais de enfermagem, pois a maioria só tem aquela renda para sustentar sua família, o que acaba tornando esses profissionais submissos e inseguros, pois são aterrorizados pelos superiores por meio de ameaças de demissão (FONTES KB, et al., 2013).

Há algumas consequências para os profissionais caso sofram algum tipo de violência no ambiente laboral, como a depressão, desvalorização do seu serviço para com os pacientes, desânimo, insatisfação no ambiente laboral e até desenvolvimento de doenças (VASCONCELLOS IRR, et al., 2012). 
Os fatores que estão relacionados com a causa da violência exercida por pacientes ou acompanhantes são na maioria das vezes a insatisfação com o atendimento prestado, diversas vezes o enfermeiro é que leva a culpa por tudo estar dando errado, pelo fato de estar mais próximo ao paciente, assim se tornando alvo de qualquer tipo de violência, seja verbal, moral ou física (TSUKAMOTO SAS, et al., 2019).

Alguns pacientes podem também estar sob efeito de entorpecentes. Em relação a equipe de atendimento de saúde, alguns fatores relacionados são: a inveja, pressão excessiva dos gestores, falta de equipamentos na unidade de saúde, sabotagem entre funcionários, entre outros (TSUKAMOTO SAS, et al., 2019).

A respeito da violência no trabalho, tem mostrado que grande parte dos profissionais são vítimas da violência durante a prestação de serviço hospitalar entre elas são: agressão física, agressão verbal, agressão psicológica, assédio moral e sexual, e isso traz grandes preocupações no que se refere a saúde mental do trabalhador. Identifica-se que os agressores desses trabalhadores são: a família do paciente, o próprio paciente, colegas de trabalho, a chefia imediata, dessa forma é viável que o serviço de saúde proporcione boas condições de trabalho e um ambiente repleto de harmonia e bons relacionamentos. Diante da violência vivenciada pelos trabalhadores, a assistência que deveria ser mais humanizada acaba sendo afetada e resultando no cuidado precário e ineficaz, favorecendo um atendimento desumano (ANGELIM RCM e ROCHA GSA, 2016).

Segundo Vieira GLC (2017) os profissionais de saúde acabam se sentindo inseguros em ambiente onde frequentemente vivenciam episódios de violência física. A literatura mostra que os profissionais enxergam tal ato de forma altamente negativa, desenvolvendo atitudes desfavoráveis no processo de cuidado aos pacientes, o que leva ao crescimento de novos episódios de agressão. Desta forma, pressupõe que a percepção de segurança no ambiente de trabalho não seja motivo de risco para ocorrência de agressão física.

Profissionais que sofrem agressão de alguma forma tendem a se sentirem mais insatisfeitos neste ambiente e assim desenvolver comportamentos psicológicos inadequados em relação aos pacientes. Em uma pesquisa a respeito da violência ao profissional de enfermagem, mostrou que os episódios de violências são atribuídos a esses profissionais são por diversos fatores, são esses: angustia e aflição de seus acompanhantes a frente de seus familiares doente, a dificuldade ao acesso de saúde e estresse diário. Contudo, a violência ocupacional no ambiente de trabalho afeta diretamente o profissional de forma negativa e assim oferecendo um atendimento insatisfatório (PEDRO DRC, et al., 2017).

Vasconcellos IRR, et al. (2012), nos mostram que os elementos responsáveis pela violência ocupacional contra o profissional de enfermagem no serviço hospitalar são os próprios pacientes e seus acompanhantes, ato que ocorre pela precarização do serviço de saúde dos hospitais públicos, a qual trabalhador age de frente, sendo assim o acaba sendo alvo do cliente, que descarrega sua insatisfação com a assistência prestada. $O$ profissional de enfermagem dentro do atendimento em hospitais públicos é apenas mais uma vítima no meio do processo precário, e o confronto entre profissionais e pacientes pode gerar um desconforto para 0 trabalhador e fazendo com que ele se sinta desvalorizado e insatisfeito.

Quando se trata das causas da violência ocupacional, há alguns fatores que favorecem para o acontecimento da violência, sendo eles: problemas organizacionais, que são relacionados à gestão hospitalar sendo a influenciadora do problema; Fatores humanos, que estão relacionados aos comportamentos antiéticos dentro de um grupo de colegas de trabalho que podem desencadear um comportamento violento; Perfil dos usuários, que são aqueles menos favorecidos economicamente, que acabam descontando suas frustrações quando não sabem lidar com o fato de estarem hospitalizados (FERNANDES APFC e PASSOS JP, 2018).

De acordo com Pai DD, et al. (2018), os profissionais sofrem de discriminação racial, assédio moral, violência física e verbal, sendo seus principais agressores os pacientes, seguido dos colegas de trabalho, seus gestores e por fim, os acompanhantes. Cita também que as causas relacionadas a esses tipos de violência são os problemas com entorpecentes e etilismo dos pacientes que são atendidos neste hospital, o que acaba tornando-os violentos, assim colocando a culpa de suas ações nos seus vícios, seguido de insatisfação com o atendimento prestado pelos profissionais. 
Abordando o assunto de forma internacional, Gonçalves AR, et al. (2018), nos diz que o fator que acaba influenciando para o estresse e adoecimento dos profissionais de enfermagem é a sua carga horária, condições de trabalho e o contato com a morte e sofrimento diariamente. Também é citado a pressão que os profissionais sofrem dos gestores, falta de recursos no hospital o que consequentemente gera atendimentos insatisfatórios.

Alguns fatores relacionados à ocorrência de violência física foram: ter presenciado alguma situação de violência no trabalho, ou seja, ser testemunha, falta de reconhecimento no trabalho. Alguns profissionais foram vítimas de assédio sexual e alguns fatores associados foram trabalhar no turno noturno e serem trabalhadores mais jovens (TSUKAMOTO SAS, et al., 2019).

Lucena PLC, et al. (2019), ressalta que as vítimas de violência não são os únicos prejudicados pelo assédio. Presenciar essas situações tornam as testemunhas alvos do agressor, causando estresse, insegurança, medo, assim podendo acarretar problemas de saúde nesses indivíduos. Além disso, sentem-se impotentes, pois suas buscas por alguma punição ao agressor e acolhimento a vítima acaba sendo em vão, sendo essas atitudes dificilmente averiguadas de forma jurídica e formal, o que faz com que a ocorrência de assédio prevaleça no local de trabalho.

Falando de estresse no trabalho em profissionais de enfermagem que trabalham no SAMU, Carvalho AEL, et al. (2020), cita fatores associados a este fenômeno, sendo eles: ser do sexo feminino, pois a mulher já tem uma carga de trabalho maior devido suas responsabilidades em casa; ambiente de trabalho insalubre; desgaste emocional e restrições na autonomia. Mostrando assim a necessidade de um acompanhamento na saúde dos profissionais de enfermagem, assim como acompanhamento das suas condições laborais.

O profissional de enfermagem enfrenta muitas dificuldades no seu cotidiano, como lidar com seus pacientes e seus acompanhantes quando tem comportamentos inapropriados, longas jornadas de trabalho, sofrer violência durante o serviço hospitalar. Tudo isso gera consequências que afetam a saúde do trabalhador tanto física quanto mental, sendo elas: depressão, estresse, exaustão, desânimo, desmotivação, trauma, desvalorização da profissão, insônia, ansiedade, frustração, e isso tudo pode afetar no atendimento prestado à população e o desempenho profissional desse indivíduo. (BORDIGNON e MONTEIRO, 2016)

Segundo Scaramal DA, et al. (2017), a violência ocupacional é um grande desafio a ser solucionado, pois esse tema vem sido pouco discutido. Levando em consideração que os profissionais são acometidos por doenças e traumas, faz com que duvidem ainda mais da sua capacidade como profissionais e questionando sobre a escolha. Cabe a esses profissionais criarem mecanismos de prevenção para minimizar as consequências causadas pela violência ocupacional.

O bullying também traz consequências na saúde mental dos trabalhadores, englobando os aspectos psicológico, físico e social. No aspecto psicológico os profissionais relatam ansiedade, tristeza, insônia, estresse; no físico, relatam cansaço, fadiga; no social relatam isolamento e afastamento do emprego por conta de muita pressão. Para sua prevenção é proposto uma capacitação e educação continuada dos profissionais sobre o bullying, a violência e como evitar esses fenômenos, assim contornando a situação e prevenindo sua integridade física e mental (TEIXEIRA A, et al., 2016).

As relações interpessoais entre profissional e paciente podem ajudar na prevenção de violência ocupacional. O profissional demonstrando empatia, fornecendo um cuidado de boa qualidade, visando à melhora do paciente tanto física quanto mentalmente é o que pode diferenciar no comportamento do paciente de forma negativa ou positiva. É preciso também ferramentas educacionais aos profissionais de enfermagem para saberem lidar com os pacientes para evitar qualquer conflito que leve à violência física (SOUZA JSR, et al., 2020).

Atualmente a situação enfrentada pelos profissionais de enfermagem precisa ser transformada Brasil afora na busca por boas condições de trabalho é necessário que todos colaborem, gestores trabalhadores, comunidade cientifica e população, planejando ações que possa minimizar a violência no trabalho, com vistas ao alcance de êxito cada vez maiores neste campo (BORDIGNON M e MONTEIRO MI, 2016). 
Vieira GLC (2017) afirma que as organizações internacionais estabeleceram um conjunto de diretrizes no enfrentamento da violência no setor de saúde, notado a tendência do crescimento da prática, que resulta de forma negativa no ambiente laboral e na saúde desses profissionais. No entanto sugere-se adesão de programas e políticas formais na prevenção da violência dentro das instituições. Para melhorar nas condições de trabalho medidas preventivas deverão ser adotadas nas instituições com a finalidade de melhorar a qualidade do serviço e as condições do ambiente laboral. São recomendadas ações que estabeleça o mapeamento onde o risco para violência é mais prevalente, cursos e treinamentos dos profissionais de saúde e assistência médica e psicológica aos que passam por essas experiências.

\section{CONSIDERAÇÕES FINAIS}

Analisa-se como a área da enfermagem pode sofrer violência ocupacional. Diante de tanta tensão que o próprio setor da saúde proporciona no trabalhador, é possível que além disso, ocorram situações que podem favorecer um estresse ainda maior. Faz-se necessário estudos sobre este determinado tema, para a obtenção de um protocolo para prevenção e conhecimento do procedimento para lidar com este cenário. Uma boa gestão, uma educação continuada com os profissionais sobre este tema, treinamento para estes profissionais antes de ingressarem em seu local de trabalho, um bom atendimento ao paciente, correções de problemas estruturais (se possível), somados podem ajudar a reduzir e/ou prevenir essa problemática que infelizmente afeta negativamente estes profissionais.

\section{REFERÊNCIAS}

1. ANDRADE CB, et al. Assédio moral no trabalho e sua complexidade: revisando as produções científicas. Journal of Research: Fundamental Care Online, 2015; 7(3): 2761-2773.

2. ANGELIM RCM, ROCHA GSA. Produção científica acerca das condições de trabalho da enfermagem em serviços de urgência e emergência. Journal of Research: Fundamental Care Online, 2016; 8(1): 3845-3859.

3. APAV - Associação Portuguesa de Apoio à Vítima. 2015. Folha Informativa: Violência Institucional. Disponível em: https://www.apav.pt/apav_v3/index.php/pt/folhas-informativas. Acesso em: dez. 2020.

4. BAENA CP. Revisão sistemática e metanálise: padrão ouro de evidência? Revista Médica da UFPR, 2014; 1(2): 7174.

5. BARBOSA R, et al. Violência psicológica na prática profissional da enfermeira. Revista da Escola de enfermagem da USP, 2011; 45(1): 26-32.

6. BERGAMASCKI G. 2018. A Violência nas Redes Sociais. Disponível em: http://www.revistamissoes.org.br/2018/11/a-violencia-nas-redes-sociais/. Acesso em: dez/2020.

7. BERLINGIERI A. Workplace bullying: exploring an emerging framework. Work, employment and society, 2015; 29(2): 342-353.

8. BORDIGNON M, MONTEIRO MI. Violência no trabalho da Enfermagem: um olhar às consequências. Revista Brasileira de Enfermagem, 2016; 69(5): 996-999.

9. CARVALHO AEL, et al. Estresse dos profissionais de enfermagem que atuam no atendimento pré-hospitalar. Revista Brasileira de Enfermagem, 2020; 73(2): 1-6.

10. 1COELHO EBS, et al. Violência: definições e tipologias, SC. Universidade Federal de Santa Catarina, Florianópolis, $2014 ; 32 \mathrm{p}$.

11. COSTA R, et al. O legado de Florence Nightingale: uma viagem no tempo. Texto Contexto Enfermagem Florianópolis, 2009; 18(4): 661-9.

12. FERNANDES APFC, PASSOS JP. Delineamento da violência sofrida pela equipe de enfermagem na emergência hospitalar. Revista de Enfermagem UERJ, 2018; 26(1): 1-5.

13. FONTES KB, et al. Fatores associados ao assédio moral no ambiente laboral do enfermeiro. Revista LatinoAmericana de Enfermagem, 2013; 21(3): 758-764.

14. FRAZÃO DA. 2020. Biografia de Florence Nightingale In: Ebiografia. Disponível em: https://www.ebiografia.com/florence_nightingale/. Acesso em: dez/2020.

15. GONÇALVES AR, et al. Stress e engagement na profissão de enfermagem: Análise de dois contextos internacionais. Revista Portuguesa de Enfermagem de Saúde Mental, 2018; Especial (6): 59-64.

16. GRIZARD N, VIEIRA ETS. Ana Néri, Madrinha da Enfermagem no Brasil, Gazeta Médica da Bahia, 2008; 78(2): 145-147.

17. LUCENA PLC, et al. Testemunhas de assédio moral na Enfermagem: identificando características desse fenômeno, sentimentos e estratégias de enfrentamento. REME - Revista Mineira de Enfermagem, 2019; 23: 1164.

18. MARTINS JT, et al. Equipe de enfermagem de emergência: riscos ocupacionais e medidas de autoproteção [Emergency nursing team: occupational risks and self protection]. Revista de Enfermagem UERJ, 2014; 22(3): 334340. 
19. MONTE PF, et al. Estresse dos profissionais enfermeiros que atuam na unidade de terapia intensiva. Acta paulista de enfermagem de São Paulo, 2013; 26(5): 421-427.

20. PAI DD, et al. Violência física e psicológica perpetrada no trabalho em saúde. Texto contexto Enfermagem Florianópolis, 2018; 27(1): 10.

21. PEDRO DRC, et al. Violência ocupacional na equipe de enfermagem: análise à luz do conhecimento produzido. Saúde debate Rio de Janeiro, 2017; 41(113): 618-629.

22. SANTANA LC, et al. Estresse ocupacional em profissionais de enfermagem de um hospital universitário. Revista Brasileira de Enfermagem, 2020; 73(2): 7.

23. SANTOS KM, et al. Perfil da equipe de enfermagem de unidades ambulatoriais universitárias: considerações para a saúde do trabalhador. Escola Anna Nery do Rio de Janeiro, 2020; 24(2): 9.

24. SCARAMAL DA, et al. Violência física ocupacional em serviços de urgência e emergência hospitalares: percepções de trabalhadores de Enfermagem. REME - Revista Mineira de Enfermagem, 2017; 21: 1-8.

25. SOUZA AAM, et al. Aspectos relacionados à ocorrência de violência ocupacional nos setores de urgência de um hospital. Revista de Pesquisa Cuidado é Fundamental Online, 2014; 6(2): 637-650.

26. SOUZA JSR, et al. Relações interpessoais entre enfermeiro-paciente na perspectiva da violência atual. Journal of Research: Fundamental Care Online, 2020; 12: 648-653.

27. TEIXEIRA A, et al. Bullying no trabalho: Perceção e impacto na saúde mental e vida pessoal dos enfermeiros. Revista Portuguesa de Enfermagem de Saúde Mental Porto, 2016; 1(15), 23-29.

28. TSUKAMOTO SAS, et al. Violência ocupacional na equipe de enfermagem: prevalência e fatores associados. Acta paulista de enfermagem de São Paulo, 2019; 32(4): 425-432.

29. VASCONCELLOS IRR, et al. Violência ocupacional sofrida pelos profissionais de enfermagem do serviço de pronto atendimento hospitalar. Revista Gaúcha de Enfermagem, 2012; 33(2): 167-175.

30. VIEIRA GLC. Agressão física contra técnicos de enfermagem em hospitais psiquiátricos. Revista Brasileira de saúde ocupacional, 2017; 42(8): 1-9. 